\title{
Nanog Is Highly Expressed in Ovarian Serous Cystadenocarcinoma and Correlated with Clinical Stage and Pathological Grade
}

\author{
Yongmiao Pan ${ }^{a}$ Jie Jiao ${ }^{b}$ Caiyun Zhou ${ }^{c}$ Qi Cheng ${ }^{b}$ Yuting Hu ${ }^{b}$ \\ Huaizeng Chen ${ }^{b}$ \\ ${ }^{a}$ Department of Obstetrics and Gynecology, b'Women's Reproductive Health Key Laboratory of Zhejiang Province, \\ and 'Department of Pathology, Women's Hospital, School of Medicine, Zhejiang University, Hangzhou, China
}

\section{Key Words}

Serous ovarian carcinoma $\cdot$ Nanog $\cdot$ Stem cell marker

\begin{abstract}
Objective: Nanog is overexpressed in embryonic stem cells for cell self-renewal and differentiation. We investigated whether the Nanog expression is associated with the occurrence and development of ovarian cancer. Methods: Immunohistochemistry was used to examine the expression of Nanog in 43 normal ovarian epithelia, 110 serous cystadenomas, 80 borderline serous cystadenomas, and 107 serous cystadenocarcinomas. In the meantime, their association with various clinicopathologic features was assessed. $\boldsymbol{R e}$ sults: The expression intensity of Nanog in normal ovarian tissue, benign, borderline, and malignant tumors showed a gradual rising trend. Among the serous cystadenocarcinomas, $42.86 \%$ were detected to be positive for stage I, $70.97 \%$ for stage II, $95.31 \%$ for stage III, and $100 \%$ for stage IV. There was a strong correlation between Nanog and clinical stage $(r=0.418, p=0.000)$. Besides, there was a $55.56 \%$ positive expression of grade $\mathrm{I}, 73.68 \%$ of grade $\mathrm{II}$, and $96.67 \%$ of grade III. The correlation between Nanog and differentiation grade was dramatic $(r=0.692, p=0.000)$. Conclusions: Nanog was highly expressed in ovarian serous cystadenocarcinoma,
\end{abstract}

and showed a positive correlation with clinical stage and grade. Nanog may play an important role in the development of dedifferentiation and progression of serous ovarian carcinoma.

Copyright $\odot 2011$ S. Karger AG, Basel

\section{Introduction}

Ovarian cancer has become a fatal threat to women's lives and health, and its mortality ranks first among gynecological malignancies. As a result of a lack of early specific symptoms and signs, newly diagnosed patients may have developed advanced cancer and missed the optimal timing of surgery. With the in-depth research of cancer stem cells, cancer-initiating cells have also been found in the epithelial ovarian cancer [1]. The cancerinitiating cells maintain their undifferentiated state through the regulation of several downstream molecules in order to retain the potential of self-renewal, invasion and metastasis. It is believed that the research on a multipotential and differentiation-related protein may contribute to the early prediction and diagnosis of ovarian cancer.

\section{KARGER}

Fax +4161306 1234 E-Mail karger@karger.ch www.karger.com
(C) 2011 S. Karger AG, Basel

$1015-2008 / 10 / 0776-0283 \$ 26.00 / 0$

Accessible online at:

www.karger.com/pat
Huaizeng Chen

Women's Reproductive Health Key Laboratory of Zhejiang Province

Women's Hospital, School of Medicine, Zhejiang University

Xueshi Road No. 2, Hangzhou, 310006 (China)

Tel. +86 5718706 1501, Fax +86 5718706 1878, E-Mail chenhz@zju.edu.cn 
Nanog, found as a new multipotent stem cell marker in 2003, is specifically expressed in the human embryonic pluripotent stem cells of embryos before or after implantation, primordial germ cells, embryonic stem cells cultured in vitro, embryonic germ cells and embryonic carcinoma cells, and functions in promoting cell proliferation. Zhang et al. [1] carried out research about the role of several stem cell transcription factors in the regulation of growth and differentiation of germ cell tumor, including Nanog. Nanog was found to be expressed in dysgerminoma and embryonic carcinoma, but not in immature teratoma, endodermal sinus tumor and choriocarcinoma. As a result, it can be used to distinguish between germ cell tumor and non-germ cell tumor. Moreover, they discovered that Nanog is a sensitive and specific marker of metastatic germ cell tumors. Chang et al. [2] and Santagata et al. [3] have recently further confirmed the above point of view.

Hence, Nanog is an emerging research focus of developmental biology, playing an important role in the maintenance of self-renewal and multipotential capacity. In our study, we examined the expression of Nanog in ovarian serous cystadenocarcinoma by immunohistochemical analysis and further explored the association between the expression of Nanog and pathological grade, clinical staging, and special serum marker.

\section{Subjects and Methods}

\section{Samples and Patients}

Three hundred and forty samples were randomly obtained from the Pathological Department of Women's Hospital, School of Medicine, Zhejiang University (China) between March 1997 and December 2008. Each patient had complete clinical data. The samples consisted of 43 normal ovarian epithelia, 110 serous cystadenomas, 80 borderline serous cystadenomas, and 107 serous cystadenocarcinomas (including 7 of stage I, 31 of stage II, 64 of stage III and 5 of stage IV). Patients who were treated with chemotherapy, immunotherapy or radiotherapy before operation have been excluded from specimen collection. The complete clinical pathologic parameters were age of the patients, expression level of CA125, clinical stage, and histologic grade [4]. This study was approved by the Ethics Committee of the Faculty of School of Medicine, Zhejiang University. All patients gave informed consent.

\section{Immunohistochemistry and Evaluation}

According to standard procedures, $10 \%$ neutralized formalin was used to fix tissue samples immediately for $24 \mathrm{~h}$ prior to processing in paraffin wax. Dewaxing and rehydration of the tissue sections followed. Hydrated autoclave pretreatment was performed by boiling the samples in $10 \mathrm{mM}$ citrate buffer ( $\mathrm{pH}$ 6.0) for $2 \mathrm{~min}$. Three-percent hydrogen peroxidase was used for $10 \mathrm{~min}$ at room temperature (RT) in order to block endogen peroxidase activity. Slides were incubated with goat anti-human Nanog polyclonal antibodies (R\&D, USA) at RT for $1 \mathrm{~h}$ followed by incubation with Dako Envision peroxidase (Dako Diagnostica, Hamburg, Germany) for 30 min at RT. At last, the slides were counterstained with Mayer's hematoxylin after adding 3,3'-diaminobenzidine tetrahydrochloride (Dako) for visualization, then slides were rinsed in tap water, dehydrated, placed in xylene, and mounted at RT. Between each step, slides needed to be washed 3 times ( 3 min in PBS). Blank controls were obtained by replacing the primary antibody with normal goat serum (Dingguo, Beijing, China).

The positive reaction of the Nanog protein is visible as brown particles in the cytoplasm. We counted 100 cells in 10 random fields ( $\times 400$ objective) and calculated the percentage of positive cells. The semiquantitative immunoreactive scoring system was evaluated based on the percentage of positive cells adding to the stain intensity [5]. As for stain intensity, negative staining was defined as 0 , weak positive with faint yellow was defined as 1 , moderate positive with brown-yellow as 2 , and strong positive with dark yellow as 3 . As for the number of positive cells, $<5 \%$ positive cells was defined as $0,<25 \%$ positive cells as $1,<75 \%$ positive cells as 2 , and $>75 \%$ positive cells as 3 . The sum of stain intensity and scores of positive cells was the result for each section. It was determined as $-(0),+(1-2),++(3-4)$, and $+++(5-6)$. The evaluation of Nanog expression was separately assessed by 2 pathologists blinded to the clinicopathologic data.

\section{Statistics}

The Kruskal-Wallis $\mathrm{H}$ and the Mann-Whitney $\mathrm{U}$ tests were used to evaluate Nanog expression between the different groups. The Spearman and Kendall tests were applied to analyze the association between the positive expression and clinical pathologic factors. The SPSS 10.0 software package for Windows was used to perform statistical analysis. A result was considered to be statistically significant when $\mathrm{p}<0.05$.

\section{Results}

\section{Immunohistochemical Detection of Nanog Expression in Different Ovarian Tissues}

The positive reaction of the Nanog protein is shown as brown-yellow particles, which were mainly located in the cytoplasm. In our study, there is a significant difference between the normal ovarian tissues and borderline serous cystadenomas $(Z=-2.843, p=0.004)$ or serous cystadenocarcinomas $(Z=-6.191, p=0.000)$. With the exception of no statistical significance between normal tissue and serous cystadenoma, the pairwise comparisons of the remaining groups have shown significant differences $(\mathrm{Z}=0.387,-8.328,-2.085 ; \mathrm{p}=0.000,0.000,0.000$; table 1$)$. Moreover, the expression intensity of Nanog in normal ovarian tissue, benign, borderline, and malignant tumors exhibited a gradual rising trend (fig. 1). 
Fig. 1. Nanog expression and localization in normal ovarian epithelia (a), benign serous cystadenoma (b), borderline serous cystadenoma (c) and serous adenocarcino$\mathrm{ma}(\mathbf{d})$. The distinct brown staining is located predominantly in the cytoplasm of positive cells.
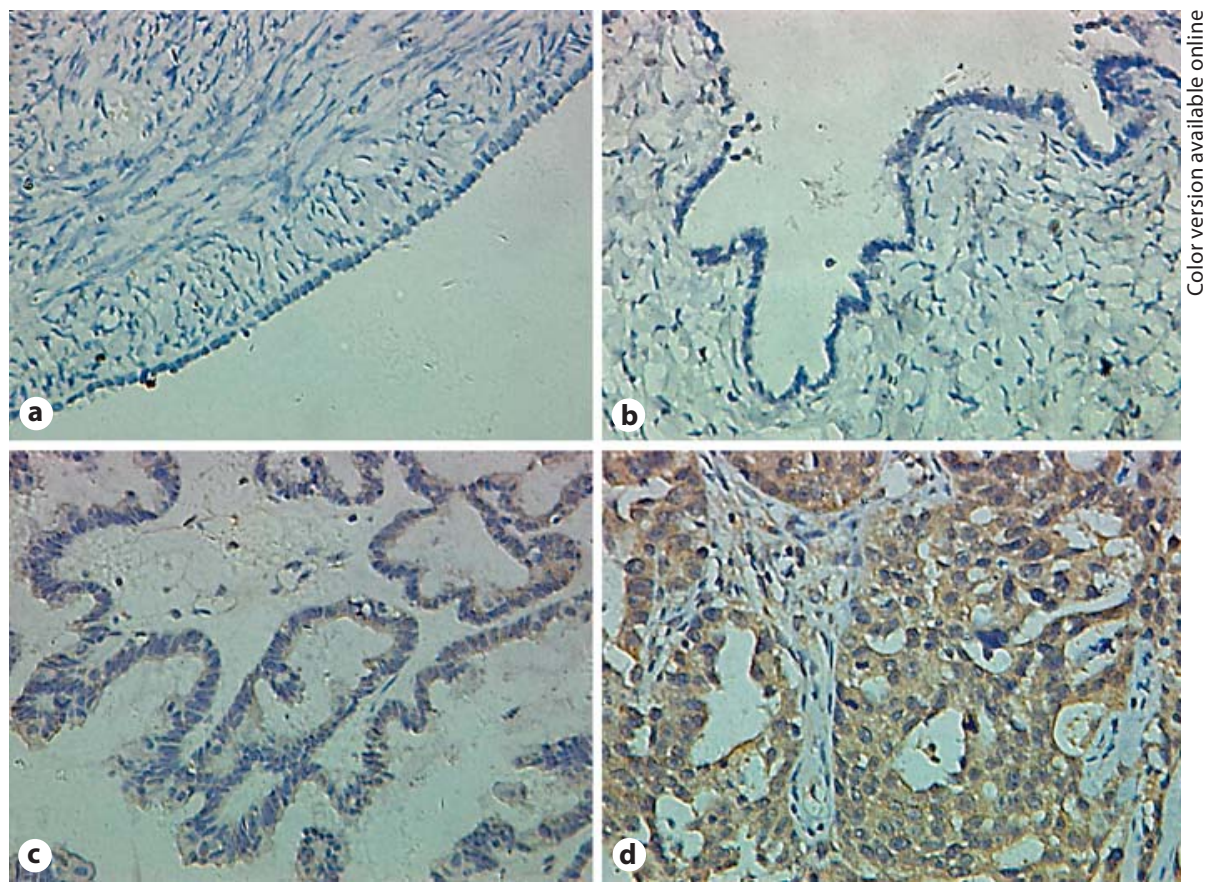

Table 1. Nanog expression in different types of ovarian tissues $(n=340)$

\begin{tabular}{|c|c|c|c|c|c|c|c|}
\hline & $\mathrm{n}$ & - & + & ++ & +++ & $\begin{array}{l}Z / \chi^{2} \\
81.314\end{array}$ & $\begin{array}{l}\mathrm{p} \\
0.000^{\mathrm{a}}\end{array}$ \\
\hline Normal ovarian epithelia & 43 & 22 & 13 & 6 & 2 & -0.163 & $0.871^{\mathrm{b}}$ \\
\hline Serous cystadenoma & 110 & 57 & 35 & 13 & 5 & -2.843 & $0.004^{\mathrm{c}}$ \\
\hline Borderline serous cystadenoma & 80 & 28 & 14 & 18 & 20 & $\begin{array}{l}-6.191 \\
-3.870\end{array}$ & $\begin{array}{l}0.000^{\mathrm{d}} \\
0.000^{\mathrm{e}}\end{array}$ \\
\hline Serous cystadenocarcinoma & 107 & 16 & 14 & 21 & 56 & $\begin{array}{l}-8.328 \\
-4.085\end{array}$ & $\begin{array}{l}0.000^{\mathrm{f}} \\
0.000^{\mathrm{g}}\end{array}$ \\
\hline
\end{tabular}

${ }^{a}$ Comparison among the 4 groups. ${ }^{\mathrm{b}}$ Normal ovarian epithelia vs. serous cystadenoma. ${ }^{\mathrm{c}}$ Normal ovarian epithelia vs. borderline serous cystadenoma. ${ }^{\mathrm{d}}$ Normal ovarian epithelia vs. serous cystadenocarcinoma. ${ }^{\mathrm{e}}$ Serous cystadenoma vs. borderline serous cystadenoma. ${ }^{\mathrm{f}}$ Serous cystadenoma vs. serous cystadenocarcinoma. ${ }^{\mathrm{g}}$ Borderline serous cystadenoma vs. serous cystadenocarcinoma.

Correlation Analysis between Nanog Expression and Clinical Parameters of Serous Ovarian Cancer

As shown in table 2, there was no correlation between age and Nanog expression ( $p>0.05)$. In all 4 groups, the CA125 level was only positively correlated with serous cystadenocarcinoma $(\mathrm{r}=0.202, \mathrm{p}=0.037)$. As shown in table 3, during the correlation analysis between Nanog expression and clinical stage, there were 3 positive expressions in 7 cases of stage I (42.86\%), 22 in 31 cases of stage II (70.97\%), 61 in 64 cases of stage III (95.31\%), and 5 in 5 cases of stage IV (100\%). The correlation coefficient was 0.418 , which showed a dramatically positive relationship $(\mathrm{p}=0.000)$. The same situation also occurs in the correlation analysis between Nanog expression and histologic grade. There were 5 positive expressions in 9 cases of grade I ( $55.56 \%), 28$ in 38 cases of grade II (73.68\%), and 58 in 60 cases of grade III (96.67\%). The correlation coefficient was $0.692(\mathrm{p}=0.000)$. 
Table 2. Correlation between Nanog expression and age, and CA125 level in different ovarian tissues

\begin{tabular}{|c|c|c|c|c|c|c|c|}
\hline & \multirow[t]{2}{*}{$\mathrm{n}$} & \multicolumn{3}{|l|}{ Age } & \multicolumn{3}{|l|}{ CA125 } \\
\hline & & mean $\pm \mathrm{SD}$, years & $\mathrm{r}$ & $\mathrm{p}$ & mean $\pm \mathrm{SD}$ & $\mathrm{r}$ & $\mathrm{p}$ \\
\hline Normal ovarian epithelia & 43 & $52.23 \pm 9.58$ & -0.272 & 0.078 & & & \\
\hline Serous cystadenoma & 110 & $44.95 \pm 14.59$ & 0.133 & 0.164 & $36.32 \pm 62.91$ & 0.143 & 0.135 \\
\hline Borderline serous cystadenoma & 80 & $38.00 \pm 9.88$ & -0.037 & 0.744 & $331.41 \pm 868.30$ & 0.031 & 0.782 \\
\hline Serous cystadenocarcinoma & 107 & $51.08 \pm 7.31$ & 0.018 & 0.852 & $1,252.31 \pm 2,335.88$ & 0.202 & $0.037^{*}$ \\
\hline
\end{tabular}

${ }^{*} \mathrm{p}<0.05$, serous cystadenocarcinoma positively correlated with serum CA125 level.

Table 3. Correlation between Nanog expression and clinical staging, and histological grade in epithelial ovarian serous cystadenocarcinoma

\begin{tabular}{lrrrrrrl}
\hline Parameter & $\mathrm{n}$ & - & + & +++ & $\mathrm{r}$ & $\mathrm{p}$ \\
\hline Clinical staging & 107 & & & & & 0.418 & $0.000^{*}$ \\
$\quad$ I & 7 & 4 & 1 & 2 & 0 & & \\
II & 31 & 9 & 8 & 4 & 10 & & \\
III & 64 & 3 & 4 & 14 & 43 & & \\
IV & 5 & 0 & 1 & 1 & 3 & & \\
Histologic grade & 98 & & & & & 0.692 & $0.000^{* *}$ \\
$\quad$ I & 9 & 4 & 3 & 2 & 0 & & \\
II & 38 & 10 & 10 & 11 & 7 & & \\
III & 60 & 2 & 1 & 8 & 49 & & \\
\hline
\end{tabular}

${ }^{*} \mathrm{p}<0.01$, positively correlated with clinical staging; ${ }^{* *} \mathrm{p}<$ 0.01 , positively correlated with histologic grade.

\section{Discussion}

In 2003, Chambers et al. [6] and other researchers almost simultaneously reported a new transcription factor, which was mainly expressed in primordial germ cells and embryonic stem cells, named Nanog [6, 7]. The human Nanog gene is located on chromosome 12p13, belonging to the pathogenic region of teratoma [8]. It has been shown that Nanog contributes to the self-renewal ability of embryonic stem cells, maintaining their undifferentiated state and promoting cell proliferation.

It has been indicated by expression profiling that Nanog is found overexpressed in pluripotent cells but downregulated after differentiation. There is no expression in normal mature organization [6]. However, the regulation of Nanog is not yet clear. The analysis of Nanog $5^{\prime}$ promoter shows that there is an Oct4/Sox 2 composite binding site motif at the upstream $180 \mathrm{bp}$ of the transcrip- tion start site, which plays an important role in the regulation of Nanog. Studies have also shown that tumor suppressor gene p53 can bind to the Nanog promoter, which plays a negative regulatory role $[9,10]$.

The 3 transcription factors Sox 2 , Oct $3 / 4$ and Nanog form a core regulatory network that coordinately determines the self-renewal and differentiation of embryonic stem cells [11,12]. Lately, in the study of prostate cancer carried out by Jeter et al. [13], the cancer cells cultured in vitro expressed Nanog. Furthermore, Nanog was found overexpressed in the stem/progenitor-like cell subsets. Tumor proliferation and colony-forming ability can be inhibited by Nanog short hairpin RNA through RNA interference-mediated Nanog knockdown trial. In the regulatory mechanism of tumor biology, the STAT signaling pathway plays an important role. As one of the STAT signaling pathway family members, STAT3 regulated tumor proliferation and antiapoptotic protein expression through functions of downstream target genes, which produced dimerization by phosphorylation of tyrosine residues [14]. In a recent study, researchers found that Nanog stimulated STAT3-specific transcriptional activation by binding to STAT3, leading to the expression of MDR gene and tumor growth. Moreover, the high expression of Nanog in Nanog-transfected cells can effectively stimulate the endogenous combination with STAT3, STAT3-specific transcriptional activation, expression of MDR gene, as well as multidrug resistance. It can be inferred that Nanog is not only a stem cell marker, but also the activator of tumorigenic pathway and MDR gene expression [15].

We found that the positive reaction of the Nanog protein is shown as brown-yellow particles located in the cytoplasm. Previous studies of germ cell tumors have demonstrated that the Nanog protein is mainly located in the nucleus; however, research on breast cancer has found 
that Nanog is not only expressed in the nucleus but also in the cytoplasm [16]. We inferred that Nanog may be related to the transcriptional regulation of cytoplasm mitochondrial DNA, besides the nuclear transcriptional regulation. Moreover, our previous study on cervical cancer has shown that the Nanog protein is located in the cytoplasm in cervical intraepithelial neoplasia tissues and cervical cancer tissues [5]; i.e., although Nanog is expressed in the nucleus in multiple tumors, it is located in the cytoplasm in both of the major gynecological neoplasms. We presumed that this phenomenon is caused by different protein function cancer cells, which may be associated with specific sex hormones.

In our study, Nanog expression showed a dramatically positive relationship with clinical stage and pathological grade, which indicated that Nanog may be involved in the development and progression from ovarian normal tissue to cancer. With the development of tumor clinical stage and pathological grade, the Nanog protein showed higher expression, which also confirmed that the protein plays an important role in the regulation of the tumor cell differentiation process. Several research papers also indicated that the Nanog protein is closely related to tumor differentiation in diverse kinds of tumors. In our study, we observed a close relationship between Nanog and differentiation grades of ovarian serous cystadenocarcinoma as well, which was consistent with previous studies. However, we also found out that there was a relationship between Nanog and the clinical stage of ovarian serous cystadenocarcinoma in the meantime, which could be explained as follows. As a result of a lack of early specific symptoms, the majority of diagnosed patients have already developed advanced cancer when they come to the doctors. In our 107 serous cystadenocarcinoma patients, the clinical stages III and IV account for 67.29\%. Moreover, most of the low differentiated ovarian cancers had been of clinical stage III or IV. Therefore, the relationship between Nanog and the histologic grade has been accompanied by the correlation between Nanog and clinical staging.

Adult stem cells have the ability to differentiate into other types of tissue cells. Similarly, different tumor cells have different differentiation grades within the same tissue; i.e. the more mature the cancer cells, the lower the degree of malignancy. It can be seen that there are many similarities as well as an inherent correlation between tumor cells and normal stem cells. As a result, cancer stem cells may have originated from the transformation of normal stem cells. As discovered in our research, Nanog expression showed a positive correlation with the tumor pathological grade as a key transcription factor during stem cell differentiation. In other words, the lower the differentiation level of the tumor tissue, the higher the expression of Nanog.

In conclusion, our results indicate that Nanog is highly expressed in serous ovarian carcinoma, suggesting that these tissues contain stem cells, embryonic-like stem cells, or cancer stem cells. As a stem cell marker, Nanog may play an important role in the development of dedifferentiation and progression of ovarian serous cystadenocarcinoma, and it may also act as a novel tumor marker.

\section{Acknowledgement}

This project was supported by a grant from the Zhejiang Natural Science Foundation of China (Y204049).

\section{References}

1 Zhang S, Balch C, Chan MW, Lai HC, Matei D, Schilder JM, Yan PS, Huang THM, Nephew KP: Identification and characterization of ovarian cancer-initiating cells from primary human tumors. Cancer Res 2008;68: 4311-4320.

2 Chang MC, Vargas SO, Hornick JL, Hirsch MS, Crum CP, Nucci MR: Embryonic stem cell transcription factors and D2-40 (podoplanin) as diagnostic immunohistochemical markers in ovarian germ cell tumors. Int J Gynecol Pathol 2009;28:347-355.
Santagata S, Ligon KL, Hornick JL: Embryonic stem cell transcription factor signatures in the diagnosis of primary and metastatic germ cell tumors. Am J Surg Pathol 2007;31: 836-845.

4 Silverberg SG: Histopathologic grading of ovarian carcinoma: a review and proposal. Int J Gynecol Pathol 2000;19:7-15.

5 Ye F, Zhou CY, Cheng Q, Shen JJ, Chen HZ: Stem-cell-abundant proteins Nanog, Nucleostemin and Musashil are highly expressed in malignant cervical epithelial cells. BMC Cancer 2008;8:108.
6 Chambers I, Colby D, Robertson M, Nichols J, Lee S, Tweedie S, Smith A: Functional expression cloning of Nanog, a pluripotency sustaining factor in embryonic stem cells. Cell 2003;113:643-655.

7 Mitsui K, Tokuzawa Y, Itoh H, Segawa K, Murakami M, Takahashi K, Maruyama M, Maeda M, Yamanaka S: The homeoprotein Nanog is required for maintenance of pluripotency in mouse epiblast and ES cells. Cell 2003;113:631-642. 
8 Clark AT, Rodriguez RT, Bodnar MS, Abeyta MJ, Cedars MI, Turek PJ, Firpo MT, Pera RAR: Human STELLAR, NANOG, and GDF3 genes are expressed in pluripotent cells and map to chromosome 12p13, a hotspot for teratocarcinoma. Stem Cells 2004; 22:169-179.

$\checkmark 9$ Rodda DJ, Chew JL, Lim LH, Loh YH, Wang B, Ng HH, Robson P: Transcriptional regulation of Nanog by Oct4 and Sox2. J Biol Chem 2005;280:24731-24737.

10 Lin TX, Chao C, Saito S, Mazur SJ, Murphy ME, Appella E, Xu Y: P53 induces differentiation of mouse embryonic stem cells by suppressing Nanog expression. Nat Cell Biol 2005;7:U165-U180.
1 Boyer LA, Lee TI, Cole MF, Johnstone SE, Levine SS, Zucker JR, Guenther MG, Kumar RM, Murray HL, Jenner RG, Gifford DK, Melton DA, Jaenisch R, Young RA: Core transcriptional regulatory circuitry in human embryonic stem cells. Cell 2005;122: 947-956.

12 Wang JL, Rao S, Chu JL, Shen XH, Levasseur DN, Theunissen TW, Orkin SH: A protein interaction network for pluripotency of embryonic stem cells. Nature 2006;444:364368.

13 Jeter CR, Badeaux M, Choy G, Chandra D, Patrawala L, Liu C, Calhoun-Davis T, Zaehres H, Daley GQ, Tang DG: Functional evidence that the self-renewal gene NANOG regulates human tumor development. Stem Cells 2009;27:993-1005.
14 Kim DJ, Chan KS, Sano S, DiGiovanni J: Signal transducer and activator of transcription 3 (Stat3) in epithelial carcinogenesis. Mol Carcinog 2007;46:725-731.

15 Bourguignon LYW, Peyrollier K, Xia WL, Gilad E: Hyaluronan-CD44 interaction activates stem cell marker Nanog, Stat-3-mediated MDR1 gene expression, and ankyrinregulated multidrug efflux in breast and ovarian tumor cells. J Biol Chem 2008;283: 17635-17651.

-16 Ezeh UI, Turek PJ, Reijo RA, Clark AT: Human embryonic stem cell genes OCT4, NANOG, STELLAR, and GDF3 are expressed in both seminoma and breast carcinoma. Cancer 2005;104:2255-2265. 